\title{
Trying to Increase Carpooling at a Major U.S. University: A Survey and an Intervention
}

Stan A. Kaplowitz ${ }^{1}$ and Arthur Slabosky ${ }^{2}$

Abstract

Many universities are attempting to reduce the $\mathrm{CO}_{2}$ emissions created by employee commuting. One way to do so is to encourage carpooling. A focus group and an online survey were performed at Michigan State University $(N=1,334)$, to determine 1.) the prevalence of carpooling among employees, 2.) the barriers employees perceive to be entailed in carpooling, and 3.) ways to reduce these barriers. Only 7 percent of those polled carpooled most of the time and only 3.7 percent carpooled at least 90 percent of the time. Surveys suggested that modest economic incentives for carpooling would not have much influence. However, making the purchase of carpool permits more convenient would have a greater effect, as would making it easier for a carpool member to occasionally drive separately at no extra cost. A major issue cited is finding carpool partners. While there is a carpooling matching website, very few people know about it. Aside from needing better publicity, respondents suggested that having access to additional information about potential partners would make them more comfortable using this website. An intervention was implemented whereby employees interested in carpooling were invited to a free lunch, to meet others whose commuting routes might make them suitable carpool partners. While fewer people attended than hoped for, approximately half of those attending either found a carpool or progressed toward this goal.

Keywords: attitudes; carpooling; incentives; ridesharing; survey; universities

\section{Introduction}

Michigan State University (MSU) is a university of 50,000 students located in East Lansing, a town of 49,000 people, in an urbanized area of 313,000 . MSU and many other universities have implemented policies to limit greenhouse gas emissions. This includes attempts to limit Scope 3 emissions, those produced by employees commuting to work. ${ }^{1}$ One way is to encourage those who drive alone to carpool.

A community-based social marketing approach ${ }^{2}$ was used to attempt to foster carpooling to and from campus. To encourage a behavior, one must first understand the perceived barriers to the action and its perceived benefits. One then needs to decrease the barriers and/or increase the benefits. This approach also uses social norms, which are especially effective when the behavior is publicly visible. Hence, the assumption was that making carpoolers visible to their peers would encourage others to emulate them.

The most obvious benefit to carpooling is sharing the operating costs (fuel, tire wear, and maintenance). The American Automobile Association (AAA) estimated the cost as 17

\footnotetext{
${ }^{1}$ Professor Emeritus, Department of Sociology, Michigan State University, East Lansing, Michigan.

${ }^{2}$ Retired Transportation Engineer, Michigan Department of Transportation, Lansing, Michigan.
} 
cents per mile for a medium-sized sedan. AAA also estimated that driving 20,000 miles (rather than 10,000) increases depreciation by 5.6 cents per mile for a medium-sized sedan. ${ }^{3}$ In addition to depreciation and maintenance, driving more miles per year wears out a car more quickly, making it necessary to replace the car sooner.

However, Wachs argued that while the cost of a car is considered in decisions about buying one, the only factors that are usually considered when planning a trip are immediate out-of-pocket costs such as fuel, parking, and tolls. ${ }^{4}$ Hence, one of the economic benefits-that carpooling reduces wear and tear on the car-is generally ignored.

Carpooling also has some obvious barriers. It requires both finding a partner and coordinating arrival and departure times and locations. It may also interfere with doing errands (e.g., delivering/picking up children, shopping) during the commuting process. ${ }^{5}$ In addition, commuters may have misgivings about their ability to handle some problems dealing with carpooling partners, for example carpool members who are late, and handling finances. ${ }^{6,7}$

In addition to these barriers, some recent social changes have been working against carpooling. Morency's study $^{5}$ of ridesharing in Greater Montreal concluded that between 1987 and 2003, the proportion of shared rides decreased. Similarly, Furuhata et al. ${ }^{8}$ reported that the ridesharing percentage in the United States declined from 20 percent in 1980 to 10 percent in 2010 . Morency saw these changes as largely a result of these factors: 1.) an increase in the average number of cars per household, which includes a decline in the proportion of households with no car; and 2.) a decline in the average household size.

The goals of the empirical research reported in this article are: to understand the extent of carpooling at MSU and to find ways to reduce the perceived barriers and increase the perceived benefits of carpooling at MSU.

\section{Methods}

Websites of all Big Ten universities and other large universities in the United States were examined. In addition, attitudes toward carpooling among employees at MSU were investigated. The first study undertaken was an online survey $(N=2,561)$, administered January-February of 2009, when gasoline prices had fallen from over $\$ 4$ per gallon the previous summer, to less than $\$ 2$ per gallon. ${ }^{9}$ The survey found that 81 percent of faculty and staff drove alone as their main transportation mode, while only 12 percent reported sharing ride/ carpool/van pool as their main mode.

People who travel farthest would save the most money by carpooling. But even among the 17 percent who traveled 20 or more miles to work one way, only 23 percent carpooled. Hence, there seemed to be much room for improvement.

A more intensive investigation of attitudes toward carpooling and ways to increase it was begun in 2012. First, three focus groups were convened, totaling 14 employees, to learn how employees saw the barriers, and benefits, thereby suggesting questions for the next large-scale online survey.

Participants were selected from employees who drove alone and commuted at least 20 miles each way. Participants were provided with lunch plus $\$ 10$ cash. As expected, partici- pants saw economic benefits to carpooling. Some also saw companionship as a benefit. As also expected, driving alone was viewed as more convenient, especially to those transporting children and those worried about needing their car for an emergency.

A major concern was finding a carpool partner. Some participants did not know how to find one; some were concerned that a partner might have habits incompatible with their own needs (e.g., smoking or transporting animals) or might even be an unsafe companion. ${ }^{9}$ Participants also noted that while a carpool parking permit would save them money in parking costs, this permit was inconvenient to obtain; unlike other permits, it could not be paid for via payroll deduction or purchased online. Instead, it required that a carpool group appear in person to obtain and pay for the permit.

\section{Online Survey August 2012}

This survey was administered when U.S. prices for regular gasoline averaged over $\$ 3.50$ per gallon. ${ }^{10}$ In addition to the issues included in the prior survey, it asked about the effect of social norms. People's environmental behavior is substantially influenced by the behavior of others and the potential approval or disapproval from others. ${ }^{11}$ However, people also underestimate the degree to which their behavior is influenced by norms. Therefore, it was assumed that 1.) normative influence from recognition might have a substantial effect on behavior, but that 2.) if respondents were directly asked if recognition would influence their behavior, they would underestimate this effect. Therefore, instead of asking respondents if this recognition would influence their behavior, they were asked if they would make use of the recognition offered. 
For this survey, 3,000 randomly selected MSU employees were invited to participate. Participants were entered in a lottery that awarded cash gifts up to $\$ 75$, and 1,334 people, whose primary work location was on campus, participated.

\section{Survey Results}

\section{How People Commute to Campus}

Each respondent was asked to estimate, to the nearest 5 percent, what percentage of their time they used for each mode of transportation. Our analysis includes those 1,240 whose percentage for different modes added up to either 100 percent or close to it (between 90\% and 110\%).

Table 1 shows that the average employee drove alone more than 80 percent of the time, and carpooled or vanpooled only 8.3 percent; results that are very similar to the 2009 survey. The data also showed that 71 percent of respondents drove alone at least 90 percent of the time, and 53 percent always did so. In contrast, only 7 percent carpooled at least 50 percent of the time and only 3.7 percent carpooled at least 90 percent of the time.

The effect of several commuting factors that might affect carpooling

Table 1. Mean Percentages That Respondents Used Each Mode

\begin{tabular}{|l|c|}
\hline \multicolumn{1}{|c|}{ Mode of Travel } & $\begin{array}{c}\text { Mean } \\
\text { Response }\end{array}$ \\
\hline Driving alone & $80.6 \%$ \\
\hline Carpooling \& Vanpooling & $8.3 \%$ \\
\hline Walking & $3.5 \%$ \\
\hline Bicycling & $4.6 \%$ \\
\hline Bus & $1.5 \%$ \\
\hline $\begin{array}{l}\text { Motor cycle/ } \\
\text { scooter \& other }\end{array}$ & $1.5 \%$ \\
\hline Total & $\mathbf{1 0 0 \%}$ \\
\hline
\end{tabular}

were also examined. A multiple regression with three predictors was performed: 1.) one-way commuting distance, 2.) the existence of a regular schedule (arrives and departs at the same time each day), and 3.) the number of days per week commuting. Both traveling farther ${ }^{12}$ and having a regular schedule ${ }^{4}$ are substantial predictors of car/vanpooling. However, the number of days coming to campus was shown to have a nonsignificant effect.

However, even among those with a regular schedule, 67 percent of respondents who commute at least 20 miles one way $(N=179)$, drive alone at least 90 percent of the time. This suggested: 1.) many employees commute far enough to save a substantial amount of money from carpooling; and 2.) interventions that overcome some of the perceived barriers might substantially increase carpooling.

\section{Parking Policies and Interest in Carpooling}

An employer can encourage carpooling by charging carpoolers less for parking than those driving alone. Like many other major universities, MSU provides a reducedcost parking permit to carpoolers. In 2012, the annual cost for a singlevehicle parking permit was $\$ 474$. A group who carpooled could purchase a carpool permit that allowed any registered car owned by members of the group to park on campus, so long as only one of these cars was on campus on any given day. The annual cost of such a permit, for a carpool of any size, was $\$ 534$. Hence, for a carpool of two, the annual cost was $\$ 267$ per person, and for a larger carpool, savings were greater. However, it was less convenient to purchase these permits (see Methods).

\section{Knowledge of Carpool Permits, Convenience of Getting One, and Convenience of Parking}

Only 44 percent of those who drove alone most of the time knew that a carpool permit could save them money. Survey questions asked respondents to rate the importance of two features of a carpool permit in encouraging carpooling: 1.) obtaining it online, and 2.) paying via payroll deduction. Results showed that 11 percent rated these features as 6 or 7 on a 1 to 7 scale, where 7 was "extremely important." Respondents were also asked how important it would be for carpooling to provide the opportunity for a more convenient parking place; 10 percent rated this feature as 6 or 7 on the same scale.

\section{Effect of Varying the Cost of Carpool Permit vs. Regular Parking Permit}

Both surveys asked about the cost of parking permits as an influence on carpooling. The 2009 survey asked: "If the annual cost of a parking permit at MSU increased from $\$ 495$ to $\$ 800$, how would this affect your interest in carpooling?” In response, 9.4 percent of those who drove alone to campus at least three days per week said they would be "very likely" to carpool.

Prior to the 2012 survey, there had been a significant increase in employee health insurance premiums, prompting an administrative decision to minimize MSU parking cost increases. Hence, the cost increases that were asked about were quite modest.

Respondents were asked to rate their interest in carpooling under four different price structures: 1.) retain current costs, 2.) decrease the total annual cost of a carpool permit by $\$ 100$ and increase the cost of a regular permit by $\$ 20,3$.) increase the annual 
Table 2. Interest in Carpooling by Number of Permission Days Available for Carpool Permits $(n=945)($ Scale $=1$ to 7)

\begin{tabular}{|l|c|c|c|}
\hline \multicolumn{1}{|c|}{ Policy } & $\begin{array}{c}\text { Mean } \\
\text { Response }\end{array}$ & $\begin{array}{c}\text { \% Not } \\
\text { Interested (1 or 2) }\end{array}$ & $\begin{array}{c}\text { \% Very } \\
\text { Interested (6 or 7) }\end{array}$ \\
\hline 1. Current: can request ONE permission day per month & $1.88^{\mathrm{a}}$ & 76.6 & 3.9 \\
\hline 2. Proposed: can request TWO permission days per month & $2.34^{\mathrm{a}, \mathrm{b}}$ & 67.7 & 8.5 \\
\hline 3. Proposed; each carpool member automatically given two all-day permits per month & $2.52^{\mathrm{b}}$ & 62.4 & 11.0 \\
\hline
\end{tabular}

Where the same superscript appears in two rows, it indicates the significance of the difference between responses to those policies.

${ }^{a}$ Comparison for these policies has $p<.001$.

${ }^{\mathrm{b}}$ Comparison for these policies has $p=.002$.

cost of regular permit by $\$ 100$, and 4 .) decrease total annual cost of carpool permit by $\$ 100$ and increase the cost of a regular permit by $\$ 100$. Among those who drove alone most of the time, and answered all four questions, none of the different policies produced responses whose differences were statistically significant.

MSU ordinarily allows only one of the vehicles associated with each carpool permit to park on campus on any given day. However, according to the 2012 university policy, each member of the carpool was allowed to bring his/her own vehicle (instead of carpooling) one day per month at no extra cost, by requesting and receiving permission of the MSU parking office. (See Table 2.)

After stating the existing policy, the survey asked about interest in carpooling: 1.) under the current policy on permission days and 2.) under some liberalized policies (asked on 7-point scale). Table 2 shows that getting two permission days per month would significantly increase interest in carpooling.

\section{Interest in Services Encouraging Carpooling}

The local bus authority has tried to reduce the community's carbon footprint through their Clean Commute Options Program (CCOP). CCOP has encouraged several alternatives to driving alone and has encouraged carpooling via a web application to help people find carpool partners. (A computer carpooling matching service, in the Greater TorontoHamilton, Ontario, Canada, area, was successful in encouraging carpool formation. ${ }^{1}$ ) As shown in Table 3 the CCOP carpool matching service was known by few, and visited by even fewer, respondents.

CCOP also encouraged carpooling by offering up to two free emergency rides home (ERH) with a rental car,

Table 3. Previous Awareness of Clean Commute Options Program (CCOP)
by Length of Commute ${ }^{a}$
\begin{tabular}{l|c|c|} 
Respondents' Awareness & $\begin{array}{c}\text { One-way commute } \\
\mathbf{1 0}-\mathbf{1 9} \text { miles \% (n) }\end{array}$ & $\begin{array}{c}\text { One-way commute } \\
\mathbf{2 0} \text { or more miles \% (n) }\end{array}$ \\
\hline Heard of CCOP & $24.5(143)$ & $21.7(129)$ \\
\hline Heard of Carpool Matching Service on Website & $9.9(141)$ & $10.1(129)$ \\
\hline Ever visited Website & $2.2(139)$ & $4.7(128)$ \\
\hline
\end{tabular}

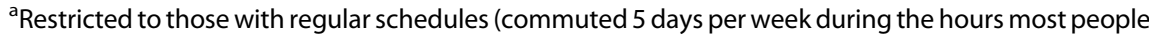
arrive at and leave campus). per six-month period, to registered carpoolers who are at work without their car. It was expected to take between 20 minutes and one hour to have access to this car.

After explaining the ERH, the survey asked: "How interested are you in finding a carpooling partner?" Among the 113 who regularly drove alone, had a regular schedule, and commuted at least 20 miles each way, 11.5 percent were very interested (6 or 7) in carpooling.

Respondents were also asked to state the maximum wait time needed for them to feel that the ERH would meet their needs: 60 percent considered anything over 20 minutes to be excessive.

\section{Information Desired about Carpool Partners}

A crucial prerequisite of carpooling is finding a suitable match. The CCOP software uses information about each commuter's residence and work location and commuting schedule to match carpool partners with others who reside and work near them. As a result of the focus groups, a survey asked if people wanted other information about potential partners before even contacting them. Results indicated that 83 percent wanted to know if a potential partner smokes, 70 percent wanted to know if the vehicle has transported animals, and 60 percent 
wanted to know whether conversation or silence is preferred.

\section{Concern for Safety}

Some focus group participants indicated concern for safety. Therefore, in the online survey, respondents were asked if they would be more comfortable knowing that their carpool partner was an MSU employee: 55 percent said they would be more comfortable having this information.

\section{Statements Clarifying Mutual Expectations}

Some focus group participants wanted a written agreement of the expectations and responsibilities of each partner. Of the survey respondents, 41 percent stated that they would like such an agreement. Of these 41 percent, 68 percent stated that they would like the CCOP website to provide guidelines for such an agreement. The survey also asked if respondents would find it useful for MSU to provide a website fully describing transportation options besides driving alone: 41 percent said Yes.

\section{Recognition of Clean Commuters}

Respondents were asked: "Suppose that people who clean commuted (i.e., use some method of commuting other than driving alone) were given an insignia to display on their clothing or on their means of transportation. If you were to qualify for such an insignia by being a clean commuter, how likely is it that you would display it?"

They were also asked: "Suppose ... clean commuters were given an annual thank you lunch. If ... (this was at a convenient location or time), how likely is it that you would attend?" Of those who answered, only 5 percent would definitely use each form of recognition. However, another 15 percent said they would probably attend the lunch and 13 percent would probably use the insignia ( 5 or more on a 7 -point scale).

While these figures may not sound impressive, of those who would probably wear the insignia, 89 percent of them drove alone at least 80 percent of the time. Suppose that with these incentives 10 percent of those who clean commute less than 20 percent of the time could be induced to clean commute 50 percent of the time. This would increase clean commuting by $2.7 \%=[(10 \% \times 89 \%) \times(50 \%$ $-20 \%)]$. Since clean commuting occurred less than 20 percent of the time (see Table 1), such a gain might make such incentives worthwhile.

\section{Carpool Lots}

The Michigan Department of Transportation has free parking lots for meeting carpool partners. Respondents were asked whether eight different lots (ranging from 7 to 20 miles from campus) might be useful places to meet a carpool partner, and 269 of the respondents who drove alone at least 80 percent of the time, said they see value in using at least one of these lots. Since there were 1,334 respondents and MSU has approximately 12,500 employees, ${ }^{13}$ this suggests that approximately $2,520[269 \times 12,500 / 1,334]$ employees might use these lots. Hence, these parking lots are worth publicizing to encourage carpooling.

\section{An Intervention: Carpool Lunch Mixers}

In the 2012 survey, 15.5 percent of respondents expressed interest in attending a mixer to find a carpool partner, and 60 percent of those said they would attend one during the noon lunch hour. In 2013, such mixers were implemented and offered a free lunch to those attending.

Flyers advertising these lunches were posted near the elevators, in 10 campus buildings and five parking ramps. Flyers were also mass e-mailed. Lunches were held in June 2013 and repeated in September to October 2013. Each brought together employees commuting via the same major route; 66 people signed up and/or came to at least one of the lunches.

In November 2013, an online survey was sent to all who had signed up for and/or attended, at least one of these lunches. Of the 36 respondents, seven had attended both lunches, 18 had attended one, and 11 had attended neither.

Table 4 shows that the probability of attending the lunch was strongly related to the length of an employee's
Table 4. Length of Commute and Likelihood of Attending Carpool Lunch ( $n=25$; attended at least one carpool lunch)

\begin{tabular}{|l|c|c|c|}
\hline $\begin{array}{c}\text { A) One-way } \\
\text { commute } \\
\text { Distance (miles) }\end{array}$ & $\begin{array}{c}\text { B) \% of } \\
\text { those attending } \\
\text { a lunch }\end{array}$ & $\begin{array}{c}\text { C) \% in } \\
\text { employee } \\
\text { sample }\end{array}$ & $\begin{array}{c}\text { Overrepresentation } \\
\text { Ratio B/C }\end{array}$ \\
\hline$<10$ & $8 \%$ & $53.2 \%$ & 0.15 \\
\hline $10-20$ & $12 \%$ & $23.6 \%$ & 0.51 \\
\hline $20-30$ & $12 \%$ & $9.6 \%$ & 1.25 \\
\hline $30-50$ & $24 \%$ & $7.4 \%$ & 3.24 \\
\hline$\geq 50$ & $44 \%$ & $6.1 \%$ & 7.21 \\
\hline
\end{tabular}


commute. While only 6 percent of those who participated in the 2012 survey lived over 50 miles from their job, those who commuted that far constituted 44 percent of lunch attendees and were overrepresented by a factor greater than 7 .

Not surprisingly, 76 percent (19 of 25) of those who attended at least one lunch have schedules in which they come to campus five days per week, arrive between 7:30 a.m. and 9 a.m., and depart between 4:30 p.m. and 6:00 p.m. Of the 25 who came to a lunch: 12 were already in a carpool. Of these 12 , eight were seeking to expand their carpool, while four were seeking to replace someone. Additionally, of these 12 , seven were in a carpool of two members (including themselves), three were in carpools of three, and two were in carpools of four.

Respondents were asked about progress toward their goal. Among attendees, out of 24 with regular schedules, six achieved their goal and another four made connections that could lead to achieving their goal.

Those who attended neither lunch were e-mailed a list of lunch participants, grouped by commuting route. Among these 10, one reported finding a partner and three others reported possibilities.

\section{Discussion}

The 2009 employee survey found that increasing the annual cost of a regular parking permit by $\$ 305$ would lead 9.4 percent of those who drove alone to be "very likely" to carpool. Such a change would approximately double the amount of carpooling. However, the modest price changes asked about in 2012 did not significantly affect interest in carpooling.
The noneconomic incentives-more convenient parking and more convenient carpool permits-would increase interest in carpooling more than the modest monetary incentives that were asked about in 2012. However, $^{3}$ the results of the 2009 survey suggest that a larger economic incentive would make a noticeable difference.

The overwhelming majority of those who drive alone were not previously aware of CCOP's attempts to encourage carpooling. Even after people were made aware of this program and website, it had only a modest effect on their interest in carpooling. The ERH had some effect and would probably have a greater effect if rides were more quickly available.

Adding two features to local carpool matching software might increase interest in using it: Assuring users that their partner would be an MSU employee; and asking users their preferences regarding their partner's behavior.

Not surprisingly, those who attended the carpool lunches were primarily those who commuted a great distance. However, only a small proportion of those who commute such distances came to a lunch. The 2012 survey found that 4.8 percent of employees commuted over 50 miles one way and drove alone more than 50 percent of the time. Given that there are approximately 12,500 employees at MSU, ${ }^{13}$ this suggests that there are approximately $600 \mathrm{MSU}$ employees who commute that far $(4.8 \%$ of $12,500=600)$ while driving alone. However, only 11 people in this category came to a lunch, less than 2 percent of those commuting that far.

While the attendance at the lunches was disappointing, many of those who attended found them useful: 25 percent of responding attendees achieved their carpool goal and another 17 percent made useful connections.

The 2012 survey responses suggest that the following policy changes may encourage carpooling:

1. Allow employees to purchase carpool permits online.

2. Allow employees to pay for carpool permits via payroll deduction.

3. Give carpoolers access to more convenient parking places.

4. Liberalize permission days for bringing one's car to campus.

5. Increase publicity for the CCOP carpool website.

6. Design the CCOP website so that it provides more information about potential carpooling partners.

7. Have the ERH provide a car more quickly.

In addition, the results of the 2009 survey suggest that a large increase in parking cost would noticeably increase carpooling.

To date, only recommendation No. 2 has been implemented. MSU is developing a plan to improve mobility on campus. As stated on their Mobility Planning webpage:

On a daily basis, there are 100s to 10 s of thousands of visitors, 32,500 students traveling to/from classes, and 12,500 employees looking for parking. On game days, there is [much more] .... All of this movement creates issues with safety, congestion and accessibility. MSU's Mobility Planning Committee continues to look at innovative ways to ... provide the framework for ... improved campus mobility for all. Part of this plan includes 
" $[\mathrm{r}]$ educing congestion on campus; Working on reducing the number of cars that are moved in a day...."14

Campus congestion and spending on parking structures can both be reduced by having employees switch from driving alone to carpooling. Hence, encouraging this switch fits well with stated MSU goals.

\section{Acknowledgments}

The studies from 2012 were supported by a Sustainability Seed Grant from Michigan State University. We thank Lauren Olsen, Kelly O'Masta, Calvin Coplai, and Shaun Piwowar for valuable research assistance with this project.

\section{Author Disclosure Statement}

No competing financial interests exist.

\section{References}

1. Carbon Trust.com. What Are Scope 3 Emissions, How Can They Be Measured and What Benefit Is There to Organisations Measuring Them? https://www.carbontrust.com/ resources/faqs/services/scope-3-in direct-carbon-emissions (last accessed 2/25/2018).
2. McKenzie-Mohr D. Fostering Sustainable Behavior, 3rd ed. New Society Publishers, Gabriola Island, British Columbia, Canada, 2011.

3. AAA. Your Driving Costs: How Much Are You Really Paying To Drive? pp. 6-7. http://exchange.aaa .com/wp-content/uploads/2017/08/170013_Your-Driving-Costs-Brochure2017-FNL-CX-1.pdf (last accessed 3/ 13/2008).

4. Wachs M. Policy implications of recent behavioral research in transportation demand management. J Plan Lit 1991;5(4):333-341.

5. Morency C. The ambivalence of ridesharing. Transportation 2007;34 (2):239-253.

6. Margolin JB, Misch MR, and Starr $M$. Incentives and disincentives of ridesharing. Transp Res Rec 1978; 673:7-15.

7. Margolin JB, and Misch MR. Incentives and Disincentives for Ridesharing: A Behavioral Study. Federal Highway Administration. U.S. Department of Transportation, Washington, DC, 1979.

8. Furuhata M, Dessouky M, Orodoñez $\mathrm{F}$, et al. Ridesharing: The state-of-the-art and future directions. Transp Res Part B: Methodological 2013;57(3):28-46. https:// doi.org/10.1016/j.trb.2013.08.012 (last accessed 2/25/2018).

9. Levin IP, and Gray MJ. Evaluation of interpersonal influences in the formation and promotion of carpools. Transp Res Rec 1970;724: 35-39.

10. U.S. Energy Information Administration. Petroleum and Other Liquids. Weekly US All Grades All Formulations Retail Gasoline Prices. https://www.eia.gov/dnav/pet/hist/ LeafHandler.ashx?n=PET\&s=EMM EPM0_PTE_NUS_DPG\&f=W 2017 (last accessed 2/25/2018).

11. Nolan JM, Schultz PW, Cialdini $\mathrm{RB}$, et al. Normative social influence is underdetected. Pers Soc Psychol Bull 2008;34(7):913-923. doi: 10.1177/ 0146167208316691.

12. Buliung RN, Soltys K, Habel C, et al. Driving factors behind successful carpool formation and use. Transp Res Rec 2009;2118:31-38. doi: 10.3141/2118-05.

13. Michigan State University. MSU Facts. https://msu.edu/about/thisismsu/ facts.html (last accessed 2/25/2018). 14. Office of the Executive Vice President for Administrative Services. Michigan State University. Mobility Planning. www.adminsv.msu.edu/ mobility/ (last accessed 2/25/2018).

Address correspondence to:

Stan A. Kaplowitz

Professor Emeritus

Department of Sociology

Michigan State University

East Lansing, MI

E-mail: Kaplowi1@msu.edu 